Currículo sem Fronteiras, v. 20, n. 1, p. 268-289, jan./abr. 2020

\title{
A CRIATIVIDADE NOS CURRÍCULOS [da Formação de Professores e Alunos, em Portugal]
}

\author{
Carla Sofia Prata Ramos Pereira \\ Instituto de Educação da Universidadede Lisboa
}

\begin{abstract}
Resumo
A importância do desenvolvimento do pensamento criativo é presença assídua nos discursos educativos das últimas décadas, nos diferentes contextos nacionais e internacionais. De que forma estarão os sistemas educativos a integrar o desenvolvimento desta competência, como elemento facilitador na resposta à complexidade dos desafios deste século? É o que tentamos perceber, observando os atuais currículos da formação de professores [nas Escolas Superiores de Educação, em Portugal] e o espaço aí ocupado pela criatividade, assim como o esforço de harmonização curricular do ensino básico, com as recomendações das organizações internacionais que o país integra. Usando uma abordagem qualitativa, de perspetiva interpretativa, este estudo usou um design metodológico que recorreu à análise documental e bibliográfica no horizonte temporal dos últimos trinta anos, com maior enfoque nos anos mais recentes. O estudo observou que a criatividade emerge nesse quadro de forma muito pontual e pouco expressiva, em raros exemplos avulsos e pouco contextualizados. Os currículos apresentam, de uma forma geral, a necessidade de novas configurações que lhes permitam uma melhor adaptação ás características sociais da contemporaneidade.
\end{abstract}

Palavras chave: Criatividade, Formação de Professores, Sociedade Contemporânea.

\begin{abstract}
The importance of the development of creative thinking is a frequent presence in the educational discourses of the last decades, in the different national and international contexts. How will education systems integrate the development of this competence as a facilitator in responding to the complexity of the challenges of this century? This is what we try to perceive, observing the current curricula of teacher training [in the Higher Education Schools in Portugal] and the space occupied by creativity, as well as the effort to harmonize basic education with the recommendations of the international organizations that the country integrates. Using a qualitative, interpretive approach, this study used a methodological design that used documentary and bibliographic analysis in the time horizon of the last thirty years, with greater focus in recent years. The study observed that creativity emerges in this context in a very punctual and not very expressive way, in rare, loose and contextualized examples. The curricula present, in a general way, the necessity of new configurations that allow them a better adaptation to the social characteristics of the contemporaneity.
\end{abstract}

Keywords: Creativity, Teacher Training, Contemporary Society. 


\section{Introdução}

Presença assídua nos discursos político, económico e educativo, a criatividade é hoje considerada, nos mais diferentes domínios, uma necessidade emergente nas sociedades contemporâneas, impondo às escolas novas exigências que passam pela capacidade de inovar estratégias e processos, preparando os futuros alunos para dominarem não só as competências consideradas tradicionais mas dotando-os também das ferramentas que lhes permitirão diferenciar-se nos mercados globais, pela sua criatividade e inovação.

"É neste contexto que a escola, enquanto ambiente propício à aprendizagem e ao desenvolvimento de competências, onde os alunos adquirem as múltiplas literacias que precisam de mobilizar, tem que se reconfigurar para responder às exigências destes tempos de imprevisibilidade e de mudanças aceleradas” (Direção Geral da Educação, 2017, p. 5). É pois neste contexto que emerge o estudo que aqui apresentamos e que inicia com uma breve referência ao conceito de currículo, como forma de esclarecer a perspetiva sobre a qual aqui nos referimos ao construto, para depois abordar o lugar da criatividade nos currículos, fazendo referência ao que observamos atualmente e o que recomendam as orientações de investigadores e instituições. Ainda sobre o lugar da criatividade nos currículos, o estudo observa alguns exemplos de escolas, projetos educativos ou reformas pioneiras, em diferentes geografias, analisando neste campo o Projeto de Autonomia e Flexibilidade Curricular implementado no ensino básico e secundário, em Portugal. Analisamos depois os planos de estudos dos cursos de formação inicial de professores e mestrados profissionalizantes, das Escolas Superiores de Educação do país, procurando perceber qual o espaço ocupado pela criatividade nestes currículos. Concluímos com as notas finais como reflexão sobre os resultados observados, fazendo ainda referência a possíveis estudos complementares.

\section{Sobre a ideia de Currículo breve nota sobre a perceção do conceito}

Com a sua inabalável versatilidade e força absorvente, o conceito de currículo é categoricamente aquele que melhor identifica quer os objetivos assacados à educação escolar quer os métodos e processos desenvolvidos pelas instituições de educação e ensino para a sua aquisição. Historicamente, transporta um valor substantivo de racionalidade e estabilidade, porque supõe sempre que feixes muito diversificados de declarações sobre factos ou ideias possam dar lugar à transmissão de conhecimentos unívocos, que se disponham organizadamente em planos seriados - por níveis, anos e ciclos - como se de uma mercadoria final efetivamente se tratasse (Ó, 2018, p. 225).

É assim em modo receituário que, numa perspetiva distante dos conceitos científicos, nos habituámos a inscrever a ideia de currículo no vocabulário profissional docente. Intermináveis, e possivelmente entediantes ao olhar de alguns, listas de conteúdos programáticos, objetivos, metas curriculares, competências, estratégias, atividades ou outros 
substantivos peculiarmente harmonizados e hierarquizados a que se associam verbos como lecionar, atingir, promover, realizar e desenvolver, entre outros, que indiciem as ações educativas esperadas de qualquer bom e obediente professor - assim caricaturamos este instrumento de que todo o docente deve apropriar-se no exercício das suas funções, sob pena de não as cumprir efetivamente.

Fica claro que a intenção não é apresentar aqui um estudo profundo e rigoroso sobre o conceito de currículo, mas apenas fazer uma breve incursão sobre a perceção que temos sobre ele, como forma de contextualizar a referência que lhe fazemos nesta viagem.

Ainda assim, impossível seria não começar por um dos prováveis inícios, como é a irresistível ideia expressa por Jonh Franklin Bobbitt, que assim se referiu ao significado latino da palavra "o currículo consiste na série de coisas que as crianças e os jovens devem experimentar para desenvolverem capacidades para fazerem as coisas bem feitas, que preencham os afazeres da vida adulta, e para serem, em todos os aspetos, o que os adultos devem ser” (Bobbitt, 2004 [1918], p.74, citado por Ó, 2018, pp. 225 e Gaspar \& Roldão, 2007, p. 21), apresentando-nos de forma aparentemente simplista uma das primeiras definições do construto, em que o currículo é considerado "um processo de racionalização de resultados educacionais, cuidadosa e rigorosamente especificados e medidos" (Silva, 2000, p. 12), integrando objetivos, procedimentos e métodos, com vista à obtenção de resultados mensuráveis (Gaspar \& Roldão, 2007; Silva, 2000).

100 anos passados observam um século de história em que muito se falou, investigou e escreveu sobre currículo, num espaço temporal que conheceu diferentes propostas teóricas, sempre associadas, é claro, às conquistas intelectuais e questões culturais que atravesaram a evolução da sociedade, assumindo-se atualmente como elemento central no processo ensinoaprendizagem. Um dos concensos que encontrámos nesta breve revisão bibliografica, e claramente o mais óbvio, foi o que se refere à dificuldade de definir objetivamente o termo, para o qual existe uma extensa pluralidade de definições ${ }^{1}$, que traduzem as diferentes perspetivas dos seus autores, sendo, como tal, adjétivado de polissémico, ambíguo, poliédrico, problemático ou conflitual (Estrela, 2011; Gaspar \& Roldão, 2007; Pacheco, 1996).

Assumindo a sua pollissemia, Pacheco observa a variabilidade do conceito em duas perspetivas particulares, uma mais rigída, referindo-se ao plano ou programa e uma mais flexível, referindo-se ao conjunto de experiências educativas vividas dentro do contexto escolar, considerando que o currículo corresponde a um projeto, uma construção interativa que implica unidade, continuidade e interdependência e deve ter em conta os contextos de implementação e as condições históricas e sociais em que se inscreve (Pacheco, 1996). Este autor assume assim o currículo como um projeto social e cultural, históricamente construído, analisado sob a perspetiva das constantes mudanças da moldura política e dos diferentes atores escolares a que está sujeito, como um projeto de formação, que a cada momento e contexto, faz e refaz a identidade dos sujeitos ${ }^{2}$ (Pacheco, 2006).

Ainda que plural e abundante em perspetivas, todas elas têm em comum o mesmo denominador, todas assentam no conjunto de conhcecimentos que deve ser ensinado implicando obviamente um processo de seleção do que se considera ser importante, válido 
ou essencial. Na perspetiva de Tadeu da Silva (2000), esta seleção deve processar-se tendo em conta o tipo de ser humano que queremos para determinada sociedade, convergindo com o ponto de vista de Pacheco quando este argumenta que o currículo deve ter em conta as questões sociais e históricas em que se insere, assumindo também a relação entre currículo e identidade, na medida em que reconhece que o currículo molda as pessoas que o seguem, contaminando inevitalvelmente a construção do $e u$.

O modo como o currículo é selecionado, organizado e transformado em territórios formativos relaciona-se diretamente com a significação atribuída ao conhecimento, num processo liderado pelas estruturas sociais, tendo em vista os propósitos educativos, as estruturas e o contexto (Pacheco, 2014). O currículo apresenta-se assim como um dispositivo de normalização ao serviço da escola, um instrumento pelo qual se procura garantir consensos e obter hegemonia, revelando-se, claramente uma questão do poder, "selecionar ou privilegiar o conhecimento que deve integrar o currículo é uma operação de poder" (Silva, 2000, p. 15) e assim o currículo, um mecanismo de dominação e poder pelo qual somos governados. Compreendendo que o currículo tem a capacidade de moldar o indivíduo, interferindo na construção da sua identidade, no sentido de lhe atribuir uma forma particular e que essa forma particular é projetada por estruturas sociais, às quais somos alheios mas pelas quais somos inevitavelmente governados, pesa por demais a responsabilidade no processo de significação atribuída ao conhecimento e na determinação dos conteúdos que vão integrar os ditos currículos, pois deste processo nascem os cidadãos que vão participar e intervir na sociedade.

Como já referido por Silva (2000), é partindo da ideia do tipo de cidadãos que queremos, que são desenhados os currículos e esta é uma grande discussão atual - que tipo de conhecimentos, que competências, que meios e estratégias se adequam às necessidades da sociedade atual.

A este respeito e tendo presente os compromissos e desafios colocados pela agenda política ${ }^{3}$, em junho de 2010, a Assembleia da República foi palco da conferência 'Que Currículo para o século XXI?', organizada pela Comissão de Educação e Ciência em parceria com o Conselho Nacional de Educação (CNE). Uma reflexão sobre questões como 'O que se pretende que os alunos aprendam na escola?', 'como preparar os cidadãos para fazerem face ao futuro?', 'Como pode a educação atuar para que os jovens estejam mais preparados para enfrentar a instabilidade no trabalho e na sociedade?' (Assembleia da República, 2010, p. 5), reconhecendo a urgência em repensar a escola, no sentido mais lato do termo, por forma a que esta seja "capaz de formar cidadãos aptos a compreender o mundo que os rodeia e de participar plenamente na sociedade” (Assembleia da República, 2010, p. 5) e considerando estas questões como essenciais na construção de um currículo para o futuro. Neste contexto, António Câmara considerou que o maior desafio para Portugal seria criar uma nova geração de exploradores, chamando a atenção para outra perspetiva que de algum modo se distancia dos tradicionais olhares sobre o currículo e sobre o seu papel na formação dos jovens,

estamos aqui a discutir currículos, mas [...] as principais características que procuramos nos trabalhadores têm muito pouco a ver com os currículos. Têm a 
ver com o facto de terem ou não paixão, de terem energia, de terem a capacidade de lidar com o stresse e com a ambiguidade, de terem autoconfiança, de terem capacidade de trabalhar em grupo, de terem capacidade para liderar grupos e de terem capacidade de concretização (Assembleia da República, 2010, p. 19),

alertando para outras dimensões que vão além do tronco comum expresso nos habituais desenhos curriculares. Ainda sobre esta conferência, sublinhamos, pela sua pertinência neste trabalho, a recomendação deixada por Maria Emília Brederode Santos no momento de encerramento, na qual, claramente nos revemos, o currículo do futuro deve contribuir para formar cidadãos mais conhecedores, mais criativos, mais responsáveis e mais autónomos, afirmando ainda que "pensar o currículo nesta perspetiva significa, pois, pensar como conseguir equilibrar um tronco comum de saberes, capacidades e atitudes indispensáveis ao cidadão de hoje, mas que inclua também a criatividade, a capacidade de escolha, a capacidade de ter e exprimir uma marca pessoal” (Assembleia da República, 2010, p. 70).

\section{A criatividade nos currículos: o que temos e o que queremos}

O discurso de Guilford (1950) na Convenção da Associação Americana de Psicologia deu início a um amplo percurso de pesquisa sobre criatividade, traduzindo-se numa pluralidade de abordagens, estruturas metodológicas, contextos de investigação e questões conceptuais cujo estudo sistemático se reflete atualmente no lugar de destaque ocupado por este conceito nas sociedades modernas, sendo visto como essencial para a inovação e para o sucesso pessoal e organizacional.

"Face à relevância atual da criatividade, é fundamental perceber que apostar no seu desenvolvimento não se trata de uma crença ou de otimismo" (Morais \& Fleith, 2017). Já em 1976, Torrance idealizava programas de treino de professores, como veículos de promoção do pensamento criativo, considerando necessário o desenvolvimento de novos instrumentos e processos de orientação educativa; alteração dos objetivos dos cursos, para inclusão do desenvolvimento de aptidões de pensamento criativo; mudanças curriculares capazes de proporcionar um ensino mais criativo; desenvolvimento de métodos e materiais que incentivassem o crescimento criativo e estimulassem os estudantes a aprender criativamente; elaboração de instrumentos para avaliar a capacidade de realização em atividades que envolvessem o pensamento criativo e alteração da relação professor-aluno no sentido do primeiro ser capaz de valorizar o pensamento criativo do segundo (Torrance, 1976).

A evolução das tecnologias de informação e comunicação provocaram mudanças na economia e transformaram toda a natureza do processo de aprendizagem, exigindo novas habilidades como sejam a capacidade de aceder, sintetizar e comunicar informações; trabalhar em colaboração com outros, na resolução de problemas complexos ou produzir conhecimento através do uso de múltiplas tecnologias. Mais do que conhecimentos tecnológicos, as Habilidades do século XXI referem-se ao conhecimento de conteúdos, alfabetização e proficiências que preparam os indivíduos para enfrentar os desafios e as 
oportunidades do mundo de hoje, privilegiando o trabalho baseado em projetos, a resolução criativa de problemas e o trabalho colaborativo (Alencar, Fleith, Boruchovitch, \& Borges, 2015; Ledward \& Hirata, 2011). A necessidade real de desenvolver futuros educacionais que abordem a integração adequada de tecnologias e abordagens sistémicas de promoção da criatividade é evidente nos discursos políticos e pedagógicos, mas os desafios em olhar além dos horizontes atuais exigem compromisso e abertura, independência da mente e coparticipação (Craft, 2008; Cremin, 2017), apelando ao pensamento coletivo e à participação ativa e responsável de todos os intervenientes, na exploração de futuros educacionais capazes de proporcionar oportunidades plurais e resultados diversos.

A par da criatividade, a comunicação, a colaboração e o pensamento crítico são atualmente considerados os ingredientes essenciais para alimentar a capacidade de inovação que o sucesso dos mercados globais exige. É, pois, nessas competências, conhecidas como $4 \mathrm{C}(\mathrm{s})$, que a escola deve hoje investir, proporcionando um desenvolvimento profissional específico aos docentes da atual e futuras gerações.

O que é necessário para promover tais propriedades e habilidades pessoais na sala de aula é infundir criatividade no currículo. Isso não envolveria abandonar os objetivos tradicionais, mas os ampliaria para incluir pensamento crítico, reconhecimento de problemas e resolução de problemas, gerando novas ideias, observando as coisas de uma nova perspetiva, observando ligações inesperadas entre informações aparentemente desconexas, e assim por diante (Cropley \& Cropley, 2018, pp. 9, tradução nossa).

Uma abordagem mais flexível dos currículos, capaz de combinar e recombinar conceitos, articular os conhecimentos das diversas áreas através de sinapses mais óbvias ou mais inesperadas, abrirá novos e distintos caminhos para a construção do conhecimento (Cropley \& Cropley, 2018).

Não obstante o reconhecimento da importância de integração da criatividade no contexto educativo, a discrepância entre esta necessidade e o serviço prestado pela generalidade das universidades continua a ser grande (Alencar \& Fleith, 2010; Cropley \& Cropley, 2018; Morais et al., 2017), revelando as contradições entre os discursos políticos e a prática educativa. $\mathrm{O}$ ensino superior, pelo lugar que ocupa e o papel que desempenha nas sociedades desenvolvidas, exige uma contínua adaptação às rápidas mudanças sociais e tecnológicas e às possibilidades que elas representam, necessitando nesse processo de capacitar todos os envolvidos, envolvendo-os de forma enriquecedora na aprendizagem, procurando o equilíbrio ente conhecimentos, habilidades e subjetivação ${ }^{4}$.

Das universidades espera-se que privilegiem uma "formação que atenda o mercado de trabalho, atualmente imprevisível e complexo, preparando profissionais que aliem a capacidade analítica a sólidos conhecimentos e competências de inovação" (David, Nakano, Morais, \& Primi, 2011, p. 14), pois representam, ao mais alto nível, o poder de construção e produção de conhecimento especializado, capaz de transformar a sociedade. Tornar as experiências educativas mais estimulantes, relevantes, dinâmicas e desafiadoras e garantir 
que os jovens adquiram competências que lhes permitam contribuir para uma economia mais criativa, parece ser uma aspiração comum aos discursos que se debruçam sobre as mudanças que devem acontecer ao nível educativo para dar resposta às necessidades da sociedade atual. O ensino superior deve ser o principal estágio para a formação especializada dos futuros profissionais da educação, para que possam trabalhar nas escolas e outros espaços de forma mais frutífera, proporcionando aos alunos as melhores estratégias para se desenvolverem de forma estruturada e eficaz (Burgo, 2016).

O currículo emerge neste contexto como o espaço mais óbvio para a promoção das capacidades criativas dos alunos, em qualquer nível de ensino, um currículo “que desperte o interesse e o prazer do aluno pelo ato de aprender e a implementação de práticas educativas que levem em consideração as características dos alunos e o acesso à informação atualizada, contextualizada e significativa” (Fleith, 2001, p. 55). Contudo, a Integração do desenvolvimento das capacidades criativas nos currículos escolares apresenta-se ainda como um árduo desafio (Craft, 2008; Eça, 2012; Fleith, 2001), no qual se procura o melhor equilíbrio entre estrutura e liberdade.

Procurando oferecer mudanças e transformações conscientes, vimos emergir alguns projetos e iniciativas que pretendem transformar aspirações em práticas informadas, em diversos países como frança, Noruega, Canadá, Austrália, China, Estados Unidos, Hungria, Islândia e Reino Unido, onde começa a observar-se a integração da criatividade nos currículos (Bereczki, 2015; Craft, 2005).

Também em Espanha, na Dinamarca e na Austrália encontramos exemplos de escolas que se distanciaram das abordagens tradicionais, adotando uma visão do ensino aparentemente mais adequada às demandas da atualidade, procurando tornar as aprendizagens mais significativas e incorporando no sistema educativo as diversas competências e habilidades que se acredita desempenharem um relevante papel na evolução das crianças e jovens, na resposta às necessidades da sociedade contemporânea. São disso exemplo o Col·legi Montserrat, em Espanha, Hellerup School na Dinamarca, Rooty Hill High School na Austrália ou Thomas Tallis School, em Inglaterra (Lucas \& Spencer, 2017) - em comum observamos o foco no aluno e no seu percurso, a promoção do trabalho colaborativo, a incidência nas abordagens interdisciplinares, o estímulo à autonomia do alunos, a adaptação dos espaços físicos à diversidade das estratégias utilizadas, a riqueza e rentabilização dos recursos, a aposta na formação dos professores e os incentivos ao envolvimento de todos os elementos da comunidade educativa.

Col·legi Montserrat (Espanha)

O Col.legi Montserrat tem na excelência humana, física, intelectual, espiritual e social dos seus alunos o objetivo global pelo qual guia os seus princípios de educação integral. Com uma pedagogia assente na teoria das inteligências múltiplas de Gardner ${ }^{5}$, o colégio oferece a todos os seus alunos diferentes oportunidades de experimentar em cada uma das áreas relacionadas com as oito inteligências, propiciando uma mais profunda compreensão ${ }^{6}$ dos diferentes campos do conhecimento. 
Tendo no aluno o principal protagonista de todo o processo ensino-aprendizagem, as estratégias passam pelo trabalho colaborativo, como forma de promover a interdependência positiva, a responsabilidade individual, as habilidades interpessoais e a avaliação individual e em grupo; o trabalho de projeto, privilegiando projetos interdisciplinares que promovam diferentes competências, projetos que favoreçam o desenvolvimento de inteligências múltiplas e facilitem a compreensão, projetos de pesquisa individual e em grupo ou projetos decorrentes de problemas da vida real; a Aprendizagem Experimental, que, usando metodologias relacionadas com design, pretende integrar os alunos no mundo real, forçando-os a afastarem-se da sua zona de conforto; a promoção do Pensamento Crítico e Criativo [através da sua integração nos conteúdos curriculares], como forma de aprender a aprender e a resolução criativa de problemas [design thinking]; o compromisso com a ética de uma Aprendizagem Global Sustentável e a possibilidade de realizar uma aprendizagem multilingue, quer seja através da integração de línguas estrangeiras nos conteúdos curriculares [aulas de história dadas em língua estrangeira, por exemplo], quer seja através de itinerários linguísticos personalizados.

\section{Hellerup School (Dinamarca)}

Hellerup School aceitou o desafio de preparar as crianças para um futuro incerto e uma sociedade nacional e global em rápida mudança. Assumindo que não conseguem prever que situações concretas que estas crianças terão de enfrentar, a escola motiva os seus alunos para a aprendizagem com novas situações, para se questionarem e para serem críticos antes de agir, orientando-os para a comunidade como seres construtivamente críticos, conhecedores e com recursos profissionais, capazes de agir em diferentes contextos culturais. Crentes de que todas as crianças devem prosperar e se desenvolver profissional e socialmente, a aposta na promoção da autoestima, na compreensão contínua de si mesmo e do seu corpo, no desenvolvimento do potencial e do talento dos alunos, observa-se na diferenciação do ensino que assenta numa ampla gama de estratégias de aprendizagem com foco em criatividade, solução de problemas e inovação. Os princípios pedagógicos alicerçam-se numa bordagem interdisciplinar com foco nas áreas de interesse dos alunos, o que permite o conhecimento e desenvolvimento das potencialidades individuais da criança - uma sala de aprendizagem flexível que enfatiza como pilares da escola, o profissionalismo académico, estético e prático.

\section{Rooty Hill High School (Austrália)}

«Equipar cada aluno para ser um aluno criativo, conectado e envolvido com o mundo em rápida transformação» e «Cultivar um sistema educacional adaptativo, inovador e em contínuo aprimoramento» são os princípios orientadores do projeto educativo de Rooty Hill High School, ancorados em valores de Participação e Entusiasmo, Excelência, Respeito e Responsabilidade, Inovação e Criatividade, Segurança e Trabalho de equipa. 
Tendo como base a «Declaração de Melbourne», de 2008, sobre metas educacionais para jovens australianos, que estabelece a meta de que todos os jovens devem se tornar aprendizes bem-sucedidos, indivíduos confiantes e criativos e cidadãos ativos e informados, o corpo docente da escola enfrentou o desafio proposto pelo Currículo Australiano [conhecimentos, habilidades e disposições que permitirão aos alunos prosperar no século XXI] de incorporar estas capacidades nos programas de aprendizagem - para isso, desenvolveu o Ciclo de Inquérito Criativo, um modelo de aprendizagem baseado em projetos, problemas e questionários. Este programa concentra-se num currículo orientado por capacidades, aprendizagem personalizada e liderança para a inovação, desenvolvendo, nos alunos, a capacidade de pensamento crítico e criativo à medida que aprendem a gerar e avaliar conhecimento, a esclarecer conceitos e ideias, a procurar possibilidades, considerar alternativas e resolver problemas.

Reconhecendo que a educação é o que as crianças necessitam para florescer no mundo como se prevê que este será, isto é, no seu mundo e não no nosso [atual], Rooty Hill promove nos seus alunos, o desenvolvimento de capacidades e disposições que acredita serem úteis para o seu futuro pessoal e profissional, tais como, razão, lógica, desenvoltura, imaginação e inovação, procurando assim contribuir para a construção de jovens realmente imaginativos, questionadores, colaborativos, persistentes e disciplinados.

Thomas Tallis School (Inglaterra)

Thomas Tallis considera-se uma escola criativa abrangente e com um amplo currículo, capaz de garantir qualidade, justiça e sucesso para todos os seus alunos [a longo prazo], assumindo a persistência, a disciplina, a imaginação, o questionamento e a colaboração como hábitos que permeiam todas as ações educativas, refletindo-se claramente nos planos curriculares. Tallis empenha-se em ajudar os alunos a desenvolver os Hábitos da Mente, potenciando disposições que irão apoiar o desenvolvimento cognitivo e a criatividade para o resto das suas vidas, adotando uma abordagem de comunidade de aprendizes que se apoiam mutuamente no sentido de serem cada vez mais curiosos, colaborativos, persistentes, disciplinados e imaginativos. Valorizando o carater dos jovens para que sejam capazes de viver bem e responsavelmente, cuidando e respeitando os outros, bem como cuidando e respeitando a si mesmos e agindo pelas razões certas, esta escola promove ainda o desenvolvimento pessoal dos seus alunos, assente em valores como justiça, honestidade, bondade, respeito e otimismo.

Estes exemplos emergem ainda, de forma mais ou menos pontual, em escolas ou colégios cuja autonomia permite cumprir os requisitos essenciais dos currículos nacionais mas também rasgar os seus limites e ir mais além, desenvolvendo outras competências e habilidades nos seus alunos, incorporando novas abordagens e estratégias, outros modos de fazer acontecer, mais estimulantes e motivadores para os jovens de hoje - destes espera-se que contagiem os currículos nacionais dos seus países. Alguns já começam a revelar a 
ousadia de se transformarem - a Islândia destaca-se por apresentar a partir de 2011 os seus currículos oficiais assentes em seis pilares fundamentais, um dos quais é a criatividade que, neste desenho curricular surge ao lado da democracia e direitos humanos, sustentabilidade, saúde e bem-estar, igualdade e alfabetização (Jónsdóttir, 2017; Patston, Cropley, Marrone, \& Kaufman, 2017); Na Hungria, o Hungarian National Core Curriculum, reconhece a criatividade como relevante em todos os domínios nas suas declarações gerais de intenção, surgindo enfatizada na área da língua, matemática, informática, educação física, estilos de vida e artes. Este currículo sublinha ainda a pedagogia criativa, propiciando oportunidades para os alunos porem em prática as suas capacidades criativas na criação e apresentação de produtos, mesmo nas áreas que não focam a criatividade em particular (Bereczki, 2015).

A Inglaterra distingue-se por implementar um dos programas mais relevantes neste processo, o Creative Partnerships (Thomson \& Sefton-Green, 2011), o qual abordaremos em particular.

\section{O exemplo do Reino Unido}

A política de currículo implementada a partir de setembro de 2008 no Reino Unido enfatiza a importância e o alcance da criatividade em cada ciclo de escolaridade, oferecendo aos professores um meio de personalizar os processos e incentivar o envolvimento dos alunos numa aprendizagem profunda. A criatividade surge posicionada, neste quadro curricular, como omnipresente e universalizada, considerando-se que é para todos e está em toda a parte, facilitando o envolvimento em trajetórias pessoais que vulgarmente se traduzem em aprendizagens efetivas (Craft, 2008).

Após a divulgação do relatório All Our Futures, o Governo do Reino Unido financiou um programa de desenvolvimento curricular em grande escala denominado «Parcerias Criativas» ${ }^{7}$, através do qual investiu em projetos educativos envolvendo artistas comunitários de todas as áreas, que, em parceria com os professores, trabalharam no sentido de nutrir e desenvolver a criatividade das crianças e jovens, adotando uma pedagogia co construtiva e co participativa, apoiando os alunos na realização das suas ideias. Em termos curriculares este projeto traduziu-se numa oferta de cinco horas semanais, tendo como objetivo incentivar a participação dos jovens como espectadores, participantes e produtores de cultura (Craft, 2008). Implementado entre 2002 e 2011, o projeto começou por explorar as interseções entre criatividade, cultura e educação procurando contribuir para uma mudança educativa, ao nível do desenvolvimento curricular e das práticas de ensino e aprendizagem, colocando os alunos no cerne de todo o processo (Sefton-Green, 2008).

Diferentes pesquisas e relatórios sobre a implementação do programa Parcerias Criativas revelaram um impacto positivo relevante sobre todos os envolvidos: crianças e jovens, pais, professores e escolas. Foi possível observar a diminuição da taxa de absentismo dos jovens, uma melhoria nas habilidades de ensino dos professores e na sua disponibilidade para assumir abordagens mais criativas; melhoraria das habilidades pessoais e sociais dos alunos e atitudes positivas por parte de professores, líderes escolares e profissionais criativos. 
Este programa interveio nas escolas ao nível da reforma curricular, desenvolvendo modelos de progressão na aprendizagem criativa, garantindo espaços para reflexão e procurando o equilíbrio entre estrutura e flexibilidade, através da aprendizagem ativa e significativa; desenvolveu uma ampla gama de iniciativas de aprendizagem de criatividade em todos os níveis do currículo, "desde projetos artísticos únicos até à alteração dos programas na globalidade da escola [...] num esforço para incorporar a criatividade num conjunto de valores distintamente contemporâneo para as escolas" (Thomson \& SeftonGreen, 2011, p. 6). A criatividade surge assim numa abordagem transversal sob o argumento de que os processos e procedimentos da educação artística modelam tipos de aprendizagem criativa que podem ser aplicados às outras áreas do currículo.

Em fevereiro de 2008 o Governo Inglês publica o Documento de Estratégia de Economia Criativa, sublinhando o valor da criatividade como um conjunto de habilidades a serem desenvolvidas, com claro foco em duas narrativas: a de fortalecer o talento dos jovens como forma de progressão na educação e nas carreiras, ao nível das indústrias artísticas, culturais e criativas; e o apoio à aprendizagem criativa consagrada na oferta de cinco horas semanais implementadas nos currículos - identificando a criatividade como uma vertente da política governamental a ser promovida em contextos de aprendizagem formal e não formal, desde os primeiros anos até ao ensino secundário.

Considerando o desenvolvimento criativo como uma das seis áreas de aprendizagem e desenvolvimento, o sistema educativo inglês inclui nos seus objetivos o compromisso de proporcionar aos alunos a compreensão de conceitos para além das fronteiras das disciplinas tradicionais como forma de responder à curiosidade e criatividade, assegurar um novo currículo que incentive a criatividade e inspire um compromisso de aprendizagem ao longo da vida. A este propósito incluiu no currículo do ensino secundário, de forma transversal às diferentes áreas, a par das habilidades funcionais em inglês, matemática e TIC, a área de «Aprendizagem e Habilidades de Pensamento Pessoal», compreendendo seis grupos de habilidades, comportamentos e qualidades pessoais: pesquisa independente; pensamento criativo; aprendizagem reflexiva; trabalho de equipa; autonomia e participação eficaz - uma gestão curricular que incentiva os alunos a pensar e trabalhar criativamente, dando-lhes as habilidades práticas para fazerem emergir as suas ideias para a vida.

\section{Projeto de Autonomia e Flexibilidade Curricular [Um modo de fazer acontecer - em Portugal]}

[...] o futuro desafia-nos a saber pensar, pelo que é necessário ir além da replicação correta de saberes, é necessário saber dar resposta, quer crítica quer criativa, aos desafios que se criam imprevisível, constante e velozmente (Almeida (coord.), 2017, p.127).

Em Portugal as políticas educativas das últimas décadas revelam um percurso pouco coerente, pautado pelas intermitências dos diferentes governos que em cada legislatura fazem 
questão de implementar novas estratégias, ora mais fechadas, ora mais abertas, fazendo dos alunos, dos professores e das escolas, constantes cobaias de experiências pouco avaliadas. Dessas experiências valorizamos as que de alguma forma abrem espaços de aprendizagem para além da memorização e estratégias diversificadas, experiências que proporcionem a todos os alunos um currículo que contemple de forma equilibrada todos os domínios do conhecimento, as artes, o desporto e a cidadania, centrado nos alunos, que privilegie o trabalho colaborativo e a interdisciplinaridade e promova a comunicação e a autonomia. Acima de tudo, um currículo que contribua para a construção de seres mais completos, capazes de se adaptar a novas situações e lidar com os desafios constantes da sociedade contemporânea.

O Projeto de Autonomia e Flexibilidade Curricular dos Ensinos Básico e Secundário ${ }^{9}$ representa uma tentativa de introduzir algumas transformações no sistema educativo destes níveis de ensino, procurando garantir que o sucesso dos alunos se traduza em aprendizagens efetivas e significativas. Implementado no ano letivo 2017/2018 em regime de experiência pedagógica (Portugal, Educação, 2017) e alargado a todo o sistema de ensino nacional no ano letivo 2018/2019, através da publicação do Decreto-Lei 55/2018 que define os princípios de organização do currículo dos ensinos básico e secundário, este projeto representa intencionalidade e ação educativa e assume-se como a operacionalização do Perfil do Aluno à Saída da Escolaridade Obrigatória, considerando que para atingir o sucesso, os cidadãos precisam integrar e relacionar conhecimentos, resolver problemas, dominar diferentes linguagens científicas e técnicas, cooperar com outros, ser autónomos, ter sensibilidade estética e artística e cuidar do seu bem-estar (Direção Geral de Educação, 2017; Portugal, Presidência do Conselho de Ministros, 2018; Portugal, Educação, 2017).

A participação no projeto Future of Education 2030, da OCDE e a promoção da iniciativa «A Voz dos Alunos», no contexto da construção de um currículo do século XXI, motivaram esta proposta do Governo que pretende valorizar a autonomia e a flexibilidade curricular, considerando a diferenciação pedagógica como um instrumento essencial para garantir melhores aprendizagens e disponibilizando instrumentos de gestão curricular que permitam a integração de diferentes estratégias, em função das necessidades dos diferentes alunos, dos contextos específicos e do Projeto Educativo de cada escola. O projeto de Autonomia e Flexibilidade Curricular assenta os seus propósitos num conjunto de princípios orientadores que regem o conceito e que tem como base essencial a promoção da melhoria da qualidade do ensino e da aprendizagem, através da utilização dos métodos, abordagens e procedimentos que se revelem mais adequados para que todos os alunos alcancem o Perfil do Aluno à Saída da Escolaridade Obrigatória (Portugal, Educação, 2017). Algumas destas estratégias, sugere o documento, que passem por uma melhor e maior articulação entre os três ciclos do ensino básico e o ensino secundário, no sentido de uma gestão integrada e sequencial do currículo, valorizando a lecionação interdisciplinar e articulada através do desenvolvimento de projetos que aglutinem aprendizagens das diferentes disciplinas. Neste contexto, assume 
a importância da natureza transdisciplinar das aprendizagens, da mobilização de literacias diversas, de múltiplas competências, teóricas e práticas, promovendo o conhecimento científico, a curiosidade intelectual, o espírito crítico e interventivo, a criatividade e o trabalho colaborativo (Portugal, Educação, 2017, p. 13883),

reconhecendo as competências que os alunos devem reunir para se preparar para os desafios do misterioso futuro. Para tal, oferece uma matriz curricular que abrange as artes, a ciência, a tecnologia, o desporto, as humanidades e a cidadania, num leque de ofertas educativas e formativas que tem nos professores os seus principais agentes de desenvolvimento, reconhecendo que nenhuma proposta de mudança ou aperfeiçoamento do sistema, por mais nobre, brilhante ou sofisticada que seja, acontece sem o profundo envolvimento dos professores, sem que estes se apropriem delas e as incorporem verdadeiramente na sua prática (Leite \& Fernandes, 2010).

\section{A Criatividade nos currículos da Formação Inicial de Professores [das Escolas Superiores de Educação $\left.{ }^{10}\right]$}

Procurando perceber se atualmente a formação inicial de Professores já integra, em alguma componente da sua estrutura, a promoção das capacidades criativas, observámos, numa primeira fase, os Planos de Estudos do ciclo conducente ao grau de Licenciado em Educação Básica das diversas Escolas Superiores de Educação (ESE) do País: Escola Superior de Educação de Beja, Escola Superior de Educação de Bragança, Escola Superior de Educação de Castelo Branco, Escola Superior de Educação de Coimbra, Escola Superior de Educação da Guarda, Escola Superior de Educação de Leiria, Escola Superior de Educação de Lisboa, Escola Superior de Educação de Portalegre, Escola Superior de Educação do Porto, Escola Superior de Educação de Setúbal, Escola Superior de Educação de Santarém, Escola Superior de Educação de Viseu, Escola Superior de Educação de Viana do Castelo, Escola Superior de Educação Jean Piaget, Escola Superior de Educação de Almeida Garrett, Escola Superior de Educação Paula Frassinetti e Escola Superior de Educação João de Deus, num total de 17 unidades orgânicas. Analisámos para tal os respetivos Despachos de homologação dos planos de estudos dos cursos, publicados em Diário da República, que datam entre 2008 e 2015 (Portugal, Ministério da Ciência, Tecnologia e Ensino Superior, 2008; Portugal, COFAC - Cooperativa de Formação e Animação, 2014; Portugal, Instituto Politécnico de Beja, 2015; Portugal, Instituto Politécnico de Bragança, 2015; Portugal, Instituto Politécnico de Castelo Branco, 2015; Portugal, Instituto Politécnico de Coimbra, 2015; Portugal, Instituto Politécnico da Guarda, 2015; Escola Superior de Educação João de Deus, 2015; Portugal, Instituto Politécnico de Leiria, 2014; Portugal, Instituto Politécnico de Lisboa, 2014) (Portugal, Direção Geral do Ensino Superior, 2014; Portugal, Instituto Politécnico de Portalegre, 2013; Portugal, Instituto Politécnico de Santarém, 2014; Portugal, Instituto Politécnico de Setúbal, 2015; Portugal, 
Instituto Politécnico de Viana do Castelo, 2015; Portugal, Instituto Politécnico de Viseu, 2015).

Estes documentos apresentam a síntese da estrutura do curso com referência às áreas científicas, distribuídas pelas diferentes componentes de formação, e créditos que devem ser reunidos para a obtenção do grau. As Didáticas Específicas, a Formação Educacional Geral, a Formação na Área da Docência e a Iniciação à Prática Profissional são componentes comuns à maioria dos currículos, mas Unidades Curriculares (UC) relacionadas com criatividade encontramos apenas três, Artes, Criatividade e Desenvolvimento, no $5^{\circ}$ semestre do curso da ESE de Leiria, Laboratório de Expressão Artística e Criatividade, no $5^{\circ}$ semestre do curso da ESE de Portalegre e Expressão, Criatividade e Jogo, no $6^{\circ}$ semestre do curso da ESE João de Deus.

A UC de Artes, Criatividade e Desenvolvimento, da ESE de Leiria, aborda a criatividade em estreita relação com o domínio artístico, em particular nos campos da Expressão Plástica/Fotografia, Expressão Musical e Expressão Dramática, enfatizando o processo criativo e a experimentação, numa unidade curricular que compreende objetivos específicos diretamente relacionados com a compreensão do valor construtivo da criatividade, o estímulo da criatividade e o reconhecimento dos seus bloqueios e a aplicação das capacidades criativas no quotidiano pessoal e profissional. O espaço ocupado pela criatividade nos conteúdos desta unidade curricular é bastante relevante, no quadro global dos itens apresentados:

Conceitos de Criatividade; Tipos de pensamento; Processos Criativos: Técnicas indutoras de Criatividade; Fundamentação teórico-prática da criatividade: Definições conceptuais e operacionais de criatividade; Desenvolvimento de habilidades de pensamento; Características do pensamento criativo; Criatividade como processo específico; Criatividade como produto; Condições para a produtividade criativa; Proc. criativos primários e secundários; Experiências criativas; Ativadores Criativos (Instituto Politécnico de Leiria, 2018/2019, p. 2).

Deixando transparecer alguma deferência que aqui é dada ao conceito de Criatividade e ao seu papel no exercício profissional dos futuros professores.

O Laboratório de Expressão Artística e Criatividade, da ESE de Portalegre, identificase como um espaço de criação artística "que pretende capacitar os estudantes, do Curso de Educação Básica, de instrumentos de criatividade e de autonomia para o seu desempenho futuro como técnicos de educação” (Instituto Politécnico de Portalegre, 2018/2019, p. 1), focando, mais uma vez, a abordagem da criatividade, nas suas possíveis interseções apenas com o domínio artístico [neste caso, nas áreas da expressão plástica, expressão musical e expressão dramática]. Nos objetivos elencados por esta unidade curricular encontramos, filiados ao conceito que procuramos, a 'compreensão da criatividade nas expressões' e o 'cruzar referências diversas em modelos de criatividade', sendo que o primeiro nos parece de espectro demasiado generalizado e o segundo relevando pouca utilidade no contexto de formação a que se refere. A criatividade não é contemplada nos conteúdos a abordar, 
emergindo, unicamente, nas metodologias a privilegiar, sob a forma de experimentação e realização de exercícios criativos.

A unidade curricular Expressão, Criatividade e Jogo, da ESE João de Deus, usa uma metodologia teórico-prática para abordar a Expressão, a criatividade e o jogo lúdico [com grande enfase neste último], no âmbito da Educação pela Arte e da Educação Artística. O jogo e a ludicidade ocupam um espaço central para onde convergem as outras áreas [Expressão e Criatividade], numa UC que privilegia a interdisciplinaridade como metodologia ativa de aprendizagem da linguagem verbal, visual, cinestésica-corporal e emocional. A criatividade não ocupa aqui lugar nos conteúdos a abordar, mas apenas no tipo de abordagem que poderá ser utilizada.

Tendo presente o atual modelo sequencial, em que ao primeiro ciclo de licenciatura se segue um segundo ciclo de mestrado, considerado como condição para a obtenção de habilitação profissional para a docência, analisámos, numa segunda fase, a estrutura curricular e os planos de estudos deste ciclo, para as especialidades que habilitam para a docência nos $1^{\circ}$ e $2^{\circ}$ ciclos de escolaridade. Esta análise recaiu sobre as mesmas 17 unidades orgânicas já mencionadas e nos Diários da República ${ }^{11}$ onde são publicados os respetivos planos de estudos destes mestrados, assim como a distribuição do número de créditos pelas componentes de formação (área de docência, área educacional geral, didáticas específicas e prática de ensino supervisionada) - onde encontrámos um total de 50 cursos de mestrados, dentro do âmbito a que nos referimos, distribuídos pelas diferentes áreas de especialidade e escolas.

Quadro 1 - Quadro síntese do número de Mestrados por área de especialidade.

\begin{tabular}{|l|c|}
\hline \multicolumn{1}{|c|}{ Áreas de Especialidade } & \multicolumn{1}{|c|}{$\begin{array}{c}\text { Número de } \\
\text { mestrados }\end{array}$} \\
\hline Educação Pré-Escolar e Ensino do $1 .^{\circ}$ Ciclo do Ensino Básico & 15 \\
\hline $\begin{array}{l}\text { Ensino do } 1{ }^{\circ} \text { Ciclo do Ensino Básico e de Português e História e Geografia de } \\
\text { Portugal no 2. }{ }^{\circ} \text { Ciclo do Ensino Básico }\end{array}$ & 12 \\
\hline $\begin{array}{l}\text { Ensino do } 1{ }^{\circ} \text { Ciclo do Ensino Básico e de Matemática e Ciências Naturais no 2. } \\
\text { Ciclo do Ensino Básico }\end{array}$ & 11 \\
\hline Ensino de Educação Musical no Ensino Básico & 3 \\
\hline Ensino de Português e Inglês no 2. ${ }^{\circ}$ ciclo do Ensino Básico & 2 \\
\hline Ensino do Inglês no 1. ${ }^{\circ}$ Ciclo do Ensino Básico & 1 \\
\hline Ensino do 1. ${ }^{\circ}$ Ciclo do Ensino Básico & 1 \\
\hline Ensino de Educação Visual e Tecnológica no Ensino Básico & 1 \\
\hline Ensino de Educação Física nos Ensinos Básico e Secundário \\
\hline Ensino do 1. ${ }^{\circ}$ Ciclo do Ensino Básico e de Matemática no 2. ${ }^{\circ}$ Ciclo do Ensino Básico \\
\hline
\end{tabular}




\begin{tabular}{|c|c|}
\hline \multicolumn{1}{|c|}{ Áreas de Especialidade } & $\begin{array}{c}\text { Número de } \\
\text { mestrados }\end{array}$ \\
\hline Ensino de Ciências Naturais no $2 .^{\circ}$ Ciclo do Ensino Básico & 1 \\
\hline
\end{tabular}

Quadro 2 - Quadro síntese da distribuição dos Mestrados que dão habilitação para a docência dos $1^{\circ}$ e $2^{\circ}$ ciclos, por escola.

\begin{tabular}{|c|c|}
\hline Escolas & $\begin{array}{c}\text { Número de mestrados } \\
\text { Profissionalizantes } \\
\left(1^{\circ} \text { e } 2^{\circ} \text { ciclo do Ensino Básico }\right)\end{array}$ \\
\hline Escola Superior de Educação de Beja & 1 \\
\hline Escola Superior de Educação de Bragança & 4 \\
\hline Escola Superior de Educação de Castelo Branco & 1 \\
\hline Escola Superior de Educação de Coimbra & 2 \\
\hline Escola Superior de Educação da Guarda & 4 \\
\hline Escola Superior de Educação de Leiria & 5 \\
\hline Escola Superior de Educação de Lisboa & 2 \\
\hline Escola Superior de Educação de Portalegre & 0 \\
\hline Escola Superior de Educação do Porto & 3 \\
\hline Escola Superior de Educação de Setúbal & 3 \\
\hline Escola Superior de Educação de Santarém & 3 \\
\hline Escola Superior de Educação de Viseu & 6 \\
\hline Escola Superior de Educação de Viana do Castelo, & 3 \\
\hline Escola Superior de Educação Jean Piaget & 5 \\
\hline Escola Superior de Educação de Almeida Garrett, & 1 \\
\hline Escola Superior de Educação Paula Frassinetti & 2 \\
\hline Escola Superior de Educação João de Deus & 3 \\
\hline
\end{tabular}

Verificados minuciosamente todos estes planos de estudos, observámos que a criatividade, ou alguma referência familiar ao conceito, está presente apenas em duas Unidades Curriculares, nos currículos de duas escolas e quatro cursos: na UC Língua, Literacia e Criatividade do curso de Mestrado em Ensino do $1 .^{\circ}$ Ciclo do Ensino Básico (CEB) e de Português, História e Geografia de Portugal no 2. ${ }^{\circ}$ CEB, da ESE de Leiria e na 
UC de Expressões e Criatividade, que integra os currículos dos mestrados em Ensino do 1. ${ }^{\circ}$ CEB e de Português e História e Geografia de Portugal no 2. ${ }^{\circ} \mathrm{CEB}$; Ensino do $1 .^{\circ} \mathrm{CEB}$ e de Matemática e Ciências Naturais no 2. ${ }^{\circ}$ CEB e Pré-escolar e Ensino do 1. ${ }^{\circ} \mathrm{CEB}$, da ESE de Viseu. Sobre esta análise, sublinhamos duas notas, o facto da ESE de Leiria ser a única escola com uma UC de Criatividade em ambos os ciclos de estudos ${ }^{12}$ e o facto de estranhamos que na ESE de Viseu a UC Expressões e Criatividade, que integra os três cursos supracitados, não faça parte do mestrado em Ensino da Educação Visual e Tecnológica, sendo esta, supostamente, uma área privilegiada para o desenvolvimento das capacidades criativas.

Da Unidade Curricular Língua, Literacia e Criatividade, da ESE, de Leiria, não conhecemos a ficha curricular, pelo que apenas podemos inferir que a abordagem ao conceito se fará, eventualmente, no domínio singular da linguagem oral e escrita, a julgar pelo próprio nome da UC e por integrar apenas o mestrado em Ensino do $1 .^{\circ}$ Ciclo do Ensino Básico (CEB) e de Português, História e Geografia de Portugal no 2. ${ }^{\circ} \mathrm{CEB}$.

Na ESE de Viseu encontramos a UC Expressões e Criatividade no plano de estudos de três mestrados, constituindo-se como uma abordagem à Educação Artística, com especial enfoque na criatividade, como mobilizadora de processos de experimentação [com recurso a diferentes linguagens: plásticas, cinestésicas, teatrais, musicais] que podem levar à produção de novos significados. O conceito que aqui mobilizamos não emerge de forma explícita nos objetivos, conteúdos ou metodologia desta Unidade Curricular, transparecendo apenas de forma subtil pela proximidade com termos ou expressões que lhe são familiares, como '...estimulem ideias', '....atitudes criativas' ou '... quadro teórico-prático... do processo criativo'.

\section{Notas finais}

Observados todos os planos de estudos das licenciaturas em Educação Básica e mestrados que habilitam para a docência dos $1^{\circ}$ e $2^{\circ}$ ciclos do ensino básico, nas diferentes áreas de especialidade, das 17 Escolas Superiores de Educação, percebemos que a criatividade emerge nesse quadro de forma muito pontual e pouco expressiva, revelando-se como exemplos avulsos e pouco contextualizados, em estruturas organizacionais que aparentam descontinuidades e incoerências. Parece-nos assim que o lugar da criatividade nos currículos da formação de professores em Portugal carece ainda de uma reflexão mais profunda (no sentido de se perceber a transversalidade do conceito, que potencialidades oferece e qual o interesse na sua exploração) e mais generalizada do ponto de vista das diferentes unidades orgânicas, no sentido de harmonizarem as competências que consideram essenciais desenvolver nos futuros professores. A reconfiguração dos curriculos escolares só poderá ser operaciomalizada por docentes que dominem já as estratégias que vão ao encontro dos centros motivacionais dos alunos, tendo presente as competências que neles pretende desenvolver - pensamos que este processo de adpatação poderá iniciar-se com a integração de uma unidade curricular de Criatividade, comunicação, colaboração e Pensamento Crítico (abordagem teórico-prática) na formação inicial de Professores do ensino básico, transversal 
a todas as áreas de docência, procurando preparar os futuros professores para as necessidades da sociedade atual.

Observa-se, desta forma, que há ainda um longo caminho a percorrer no que à adaptação da Formação de Professores à sociedade contemporânea diz respeito, em particular no que se refere à atualização dos currículos tendo em conta as constantes mutações sociológicas, a experiência de países vizinhos, os dados obtidos pelos inúmeros estudos científicos que se debruçaram sobre estas questões, as orientações da OCDE ou as recomendações da Comissão Europeia.

\section{Notas}

1. Tadeu da Silva argumenta, Neste sentido, que a noção de currículo não define exatamente o que é o currículo, revelando apenas o que "determinada teoria pensa sobre o que o currículo é” (2000, p.14).

2. Embora lhe reconheça atualmente um significado diferente, Pacheco (1996) assume que o termo currículo continua a ser utilizado como equivalente a um plano de estudos ou plano curricular.

3. Referindo-se, à data, ao Tratado de Lisboa, atualizado pelas metas para 2020, ao Processo de Bolonha e à participação nas metas 2021 definidas pela união dos países ibero-americanos.

4. Aqui entendida como a construção de si mesmo por parte do sujeito, referindo-se a características de qualidade como independência, raciocínio critico, autonomia, etc.

5. A teoria das Inteligências Múltiplas, desenvolvida por Howard Gardner, define oito inteligências, a linguística, a lógicomatemática, a Visual-espacial, a musical, a cinestésico-corporal, a interpessoal e a naturalista.

6. A compreensão é aqui entendida como a capacidade de aplicar conceitos e conhecimentos em diversos contextos de forma flexível e fluída.

7. Programa Parcerias Criativas (Creative Partnerships) - Programa de Aprendizagem Criativa desenvolvido e implementado no Reino Unido pelo CCE, entre 2002 e 2011 (altura e que foi retirado o financiamento do Concelho de Artes Inglês, no contexto de outros cortes nos financiamentos governamentais), período durante o qual trabalhou com mais de um milhão de crianças 90000 professores, envolvidos em mais de 8000 projetos, distribuídos por mais de 5000 escolas. Concebido para desenvolver as habilidades dos jovens em toda a Inglaterra, elevou as suas aspirações e conquistas, abrindo mais oportunidades para o futuro.

8. Tradução nossa do inglês "from one-off arts projects to whole-school change programmes... in an effort to programmatize this turn towards the creative as a distinctively contemporary set of values for schools" (Thomson \& Sefton-Green, Researching Creative Learning: methods and issues, 2011, p. 6).

9. O projeto de autonomia e flexibilidade curricular dos ensinos básico e secundário em regime de experiência pedagógica foi autorizado pelo Despacho n. ${ }^{\circ}$ 5908/2017, publicado em Diário da República n. ${ }^{\circ}$ 128/2017, Série II de 2017-07-05, tendo sido implementado no ano escolar de 2017-2018 em 236 escolas (171 escolas públicas, 61 privadas e quatro escolas portuguesas no estrangeiro).

10. No contexto da Formação inicial de professores dos $1^{\circ}$ e $2^{\circ}$ ciclos do ensino bárico, as Escolas Superiores de Educação, merecem ser aqui o foco da investigação pelo facto de terem sido criadas com esse fim específico.

11. (Portugal, Instituto Politécnico de Beja, 2015; Portugal, Instituto Politécnico de Bragança, 2016; Portugal, Instituto Politécnico de Bragança, 2016; Portugal, Instituto Politécnico de Bragança, 2016; Portugal, Instituto Politécnico de Bragança, 2018; Portugal, Instituto Politécnico de Castelo Branco, 2013; Portugal, Instituto Politécnico de Castelo Branco, 2015; Portugal, Instituto Politécnico de Coimbra, 2015; Portugal, Instituto Politécnico de Coimbra, 2015; Portugal, Instituto Politécnico da Guarda, 2015) (Portugal, Instituto Politécnico da Guarda, 2015; Portugal, Instituto Politécnico da Guarda, 2015; Portugal, Instituto Politécnico da Guarda, 2015; Portugal, Instituto Politécnico de Leiria, 2015; Portugal, Instituto Politécnico de Leiria, 2015; Portugal, Instituto Politécnico de Leiria, 2015; Portugal, Instituto Politécnico de Leiria, 2012; Portugal, Instituto Politécnico de Leiria, 2015; Portugal, Instituto Politécnico de Lisboa, 2015; Portugal, Instituto Politécnico de Lisboa, 2016) (Portugal, Instituto Politécnico do Porto , 2015; Portugal, Instituto Politécnico do Porto, 2015; Portugal, Instituto Politécnico do Porto , 2015; Portugal, Instituto Politécnico de Setúbal, 
2015; Portugal, Instituto Politécnico de Setúbal, 2015; Portugal, Instituto Politécnico de Santarém, 2015; Portugal, Instituto Politécnico de Santarém, 2016; Portugal, Instituto Politécnico de Santarém, 2015; Portugal, Instituto Politécnico de Viseu , 2015; Portugal, Instituto Politécnico de Viseu, 2015) (Portugal, Instituto Politécnico de Viseu, 2017; Portugal, Instituto Politécnico de Viseu, 2016; Portugal, Instituto Politécnico de Viseu, 2015; Portugal, Instituto Politécnico de Viseu, 2015; Portugal, Instituto Politécnico de Viana do Castelo, 2017; Portugal, Instituto Politécnico de Viana do Castelo, 2015; Portugal, Instituto Politécnico de Viana do Castelo, 2015; Portugal, Instituto Piaget Cooperativa para o Desenvolvimento Humano, Integral e Ecológico, C. R. L., 2018; Portugal, Instituto Piaget Cooperativa para o Desenvolvimento Humano, Integral e Ecológico, C. R. L., 2015) (Portugal, Instituto Piaget Cooperativa para o Desenvolvimento Humano, Integral e Ecológico, C. R. L., 2015; Portugal, Instituto Piaget Cooperativa para o Desenvolvimento Humano, Integral e Ecológico, C.R.L., 2017; Portugal, Instituto Piaget Cooperativa para o Desenvolvimento Humano, Integral e Ecológico, C. R. L., 2015; Portugal, COFAC - Cooperativa de Formação e Animação Cultural, C. R. L., 2015; Portugal, Escola Superior de Educação Paula Frassinetti, 2015; Portugal, Província Portuguesa do Instituto das Irmãs de Santa Doroteia, 2015; Escola Superior de Educação João de Deus, 2015)(Portugal, Instituto Politécnico de Beja, 2015; Portugal, Instituto Politécnico de Bragança, 2016; Portugal, Instituto Politécnico de Bragança, 2016; Portugal, Instituto Politécnico de Bragança, 2016; Portugal, Instituto Politécnico de Bragança, 2018; Portugal, Instituto Politécnico de Castelo Branco, 2013; Portugal, Instituto Politécnico de Castelo Branco, 2015; Portugal, Instituto Politécnico de Coimbra, 2015; Portugal, Instituto Politécnico de Coimbra, 2015; Portugal, Instituto Politécnico da Guarda, 2015) (Portugal, Instituto Politécnico da Guarda, 2015; Portugal, Instituto Politécnico da Guarda, 2015; Portugal, Instituto Politécnico da Guarda, 2015; Portugal, Instituto Politécnico de Leiria, 2015; Portugal, Instituto Politécnico de Leiria, 2015; Portugal, Instituto Politécnico de Leiria, 2015; Portugal, Instituto Politécnico de Leiria, 2012; Portugal, Instituto Politécnico de Leiria, 2015; Portugal, Instituto Politécnico de Lisboa, 2015; Portugal, Instituto Politécnico de Lisboa, 2016) (Portugal, Instituto Politécnico do Porto , 2015; Portugal, Instituto Politécnico do Porto, 2015; Portugal, Instituto Politécnico do Porto , 2015; Portugal, Instituto Politécnico de Setúbal, 2015; Portugal, Instituto Politécnico de Setúbal, 2015; Portugal, Instituto Politécnico de Santarém, 2015; Portugal, Instituto Politécnico de Santarém, 2016; Portugal, Instituto Politécnico de Santarém, 2015; Portugal, Instituto Politécnico de Viseu , 2015; Portugal, Instituto Politécnico de Viseu, 2015) (Portugal, Instituto Politécnico de Viseu, 2017; Portugal, Instituto Politécnico de Viseu, 2016; Portugal, Instituto Politécnico de Viseu, 2015; Portugal, Instituto Politécnico de Viseu, 2015; Portugal, Instituto Politécnico de Viana do Castelo, 2017; Portugal, Instituto Politécnico de Viana do Castelo, 2015; Portugal, Instituto Politécnico de Viana do Castelo, 2015; Portugal, Instituto Piaget Cooperativa para o Desenvolvimento Humano, Integral e Ecológico, C. R. L., 2018; Portugal, Instituto Piaget Cooperativa para o Desenvolvimento Humano, Integral e Ecológico, C. R. L., 2015) (Portugal, Instituto Piaget Cooperativa para o Desenvolvimento Humano, Integral e Ecológico, C. R. L., 2015; Portugal, Instituto Piaget Cooperativa para o Desenvolvimento Humano, Integral e Ecológico, C.R.L., 2017; Portugal, Instituto Piaget Cooperativa para o Desenvolvimento Humano, Integral e Ecológico, C. R. L., 2015; Portugal, COFAC - Cooperativa de Formação e Animação Cultural, C. R. L., 2015; Portugal, Escola Superior de Educação Paula Frassinetti, 2015; Portugal, Província Portuguesa do Instituto das Irmãs de Santa Doroteia, 2015; Escola Superior de Educação João de Deus, 2015).

12. Disciplina de Laboratório de Expressões Artística e Criatividade, no $5^{\circ}$ semestre do curso de licenciatura em educação básica e disciplina Língua, Literacia e Criatividade do curso de Mestrado em Ensino do $1 .^{\circ}$ Ciclo do Ensino Básico (CEB) e de Português, História e Geografia de Portugal no 2. ${ }^{\circ}$ CEB.

\section{Referências}

ALMEIDA, L. S. (. ). Criatividade e pensamento crítico: conceito, avaliação e desenvolvimento. Gondomar: Centro de Estudos e Recursos em Psicologia, 2017.

BERECZKI, E. O. Mapping creativity in the Hungarian National Core Curriculum: a content analysis of the overall statements of intent, curricular areas and education levels. The Curriculum Journal, 2015. 1-38.

BURGO, F. Aprendizagem e Criatividade no Ensino Superior: Metodologias de trabalho para os Professores de Artes Visuais. Matéria Prima: Práticas Artísticas no Ensino Básico e Secundário, Vol. 4 (1), 2016. 121-132. 
CRAFT. Creativity in Schools: Tensions and Dilemmas. [S.l.]: [s.n.], 2008. Disponivel em: <file:///C:/Users/Afonso/Downloads/Creativity_in_Schools_Tensions_and_Dilemmas.pdf>.

CREMIN, T. Creative teachers and creative teaching. In: BREEZE, R.; GUINDA, C. S. Essential Competencies for English-medium University Teaching. [S.l.]: Springer, 2017. p. 99-116.

CROPLEY, D. H.; CROPLEY, A. J. Key readings on critical thinking and creativity in the classroom. Preprint, 2018.

DAVID, A. P. et al. Competências criativas no Ensino Superior. In: WECHSLER, S.; (ORGS.), S. \&. T. N. Criatividade no Ensino Superior: Uma perspectiva internacional. São Paulo: Vetor, 2011. p. 14-53.

DIREÇÃO GERAL DA EDUCAÇÃO. Perfil dos Alunos à Saída da Escolaridade Obrigatória. Lisboa. 2017.

EÇA, T. Chemins croisés: Um regard sur l'éducation artistique. Sociétés, 2012. 77-85.

ESCOLA SUPERIOR DE EDUCAÇÃO JOÃO DE DEUS. Aviso nº2758/2015. Diário da República, $2^{\mathrm{a}}$ Série - No51, 13 março 2015. 6313-6314.

FLEITH, D. D. S. Criatividade: Novos conceitos e Ideias, Aplicabilidade à Educação. Revista Educação Especial. N17, 2001. 55-61.

FLEITH, D. D. S.; MORAIS, M. D. F. Desenvolvimento e Promoção da Criatividade. In: (ORG.), L. S. A. Criatividade e pensamento crítico: Conceito, avaliação e desenvolvimento. Porto: CERPSI, 2017. p. 4574.

GASPAR, M. I.; ROLDÃO, M. D. C. Elementos do desenvolvimento curricular. Lisboa: Universidade Aberta, 2007.

JÓNSDÓTTIR, S. R. Narratives of creativity: How eight teachers on four schoollevels integrate creativity into teaching and learning. Thinking Skills and Creativity, p. 127-139, 2017.

LEITE, C.; FERNANDES, P. Desafios aos professores na construção de mudanças educacionais e curriculares: que possibilidades e que constrangimentos? Educação, Porto Alegre, v. 33, n. 3, set./dez. 2010. 198-204.

LUCAS, B.; SPENCER, E. Teaching Creative Thinking: Developing learners who generate ideas and can think critically. Carmarthen : Crown House Publishing Limited, 2017.

MARQUIS, E.; HENDERSON, J. A. Teaching Creativity Across Disciplines. Canadian Journal of Higher Education Revue canadienne d'enseignement supérieur Volume 45, No. 1, 2015. 148-166.

MORAIS, M. D. F.; FLEITH, D. D. S. Conceito e avaliação de criatividade. In: (ORG.), L. S. A. Criatividade e pensamento crítico: Conceito, avaliação e desenvolvimento. Porto: CERPSI, 2017. p. 19-44.

Ó, J. R. D. Relatório da Unidade Curricular: Seminário de Investigação e Orientação: A Escrita Científica e a Formação Avançada. Lisboa: Universidade de Lisboa, 2018.

OCDE - CENTRE FOR EDUCATIONAL RESEARCH AND INNOVATION. Fostering and Assessing Student's Creativity and Critical Thinking in Higher Education. Workshop Summary Report. Paris: [s.n.]. 2016.

PACHECO, J. A. Currículo: teoria e práxis. Porto: Porto Editora. Porto: Porto Editora, 1996.

PACHECO, J. A. Currículo, investigação e mudança. In: LIMA, L. C., et al. A Educação em Portugal (19862006): Alguns contributos de investigação. Lisboa: Sociedade Portuguesa de Ciências da Educação, 2006. p. 67-136.

PACHECO, J. A. Educação, formação e conhecimento. Porto: Porto Editora, 2014.

PATSTON, T. J. et al. Teacher Self-concepts of Creativity: Meeting the Challenges of the 21st Century Classroom. International Journal of Creativity and Problem Solving, 27:2, 2017. 23-34.

PORTUGAL, COFAC - COOPERATIVA DE FORMAÇÃO E ANIMAÇÃO. Despacho n. ${ }^{\circ}$ 10724/2014. Diário da República, 2. ${ }^{\text {a }}$ série - Nº 158, 19 agosto 2014. 21626-21629. 
PORTUGAL, DIREÇÃO GERAL DO ENSINO SUPERIOR. Despacho n. ${ }^{\circ}$ 13402/2014. Diário da República, 2. ${ }^{\mathrm{a}}$ série - $\mathbf{N}^{\mathbf{0}}$ 213, 4 novembro 2014. 27824-27826.

PORTUGAL, EDUCAÇÃO. Despacho n. ${ }^{\circ}$ 5908/2017. Diário da República, 2. a série - N. ${ }^{0} 128$, 5 julho 2017. 13881-13890.

PORTUGAL, INSTITUTO POLITÉCNICO DA GUARDA. Despacho n. ${ }^{\circ}$ 936/2015. Diário da República, 2. ${ }^{a}$ série - No 20, 29 janeiro 2015. 2806-2809.

PORTUGAL, INSTITUTO POLITÉCNICO DE BEJA. Despacho n. ${ }^{\circ}$ 14079/2015. Diário da República, 2. ${ }^{a}$ série - $\mathbf{N}^{\mathbf{0}} \mathbf{2 3 4}, 30$ novembro 2015. 34781-34783.

PORTUGAL, INSTITUTO POLITÉCNICO DE BRAGANÇA. Despacho n. ${ }^{\circ}$ 3477/2015. Diário da República, 2. ${ }^{\text {a }}$ série - N$^{\mathbf{0}} \mathbf{6 6}, 6$ abril 2015. 8324-8325.

PORTUGAL, INSTITUTO POLITÉCNICO DE CASTELO BRANCO. Despacho n. 3051/2015. Diário da República, 2. ${ }^{\text {a }}$ série - No 59, 25 março 2015. 7416-7419.

PORTUGAL, INSTITUTO POLITÉCNICO DE COIMBRA. Despacho n. ${ }^{\circ}$ 4793/2015. Diário da República, 2. ${ }^{\text {a }}$ série - $\mathbf{N}^{\mathbf{0}} \mathbf{8 9}, 8$ maio 2015. 11347-11350.

PORTUGAL, INSTITUTO POLITÉCNICO DE LEIRIA. Despacho n. ${ }^{\circ}$ 9509/2014. Diário da República, 2. ${ }^{a}$ série - No 139, 22 julho 2014. 18828-18831.

PORTUGAL, INSTITUTO POLITÉCNICO DE LISBOA. Despacho (extrato) n. ${ }^{\circ}$ 14904/2014. Diário da República, 2. ${ }^{\text {a }}$ série - $\mathbf{N}^{\mathbf{0}}$ 237, 9 dezembro 2014. 30757-30759.

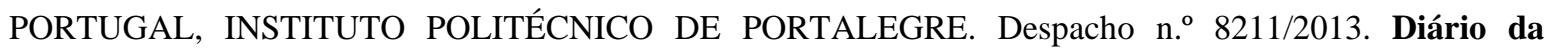
República, 2. ${ }^{\text {a }}$ série - No119, 24 junho 2013. 19877-19880.

PORTUGAL, INSTITUTO POLITÉCNICO DE SANTARÉM. Despacho n. ${ }^{\circ}$ 15080/2014. Diário da República, 2. ${ }^{\text {a }}$ série - $\mathbf{N}^{\mathbf{0}}$ 239, 22 dezembro 2014. 31032-31034.

PORTUGAL, INSTITUTO POLITÉCNICO DE SETÚBAL. Despacho n. ${ }^{\circ}$ 10548/2015. Diário da República, 2. ${ }^{\text {a }}$ série - $\mathbf{N}^{\mathbf{0}} \mathbf{1 8 5}, 22$ setembro 2015. 27340-27342.

PORTUGAL, INSTITUTO POLITÉCNICO DE VIANA DO CASTELO. Despacho n. ${ }^{\circ}$ 4628/2015. Diário da República, 2. ${ }^{\text {a }}$ série - $\mathbf{N}^{\mathbf{0}} \mathbf{8 7}, 6$ maio 2015. 11071-11073.

PORTUGAL, INSTITUTO POLITÉCNICO DE VISEU. Despacho (extrato) n. ${ }^{\circ}$ 4243/2015. Diário da República, 2. ${ }^{\text {a }}$ série - N. ${ }^{\circ} \mathbf{8 1}$ - 27 de abril de 2015, 27 abril 2015. 10342-10344.

PORTUGAL, MINISTÉRIO DA CIÊNCIA, TECNOLOGIA E ENSINO SUPERIOR. Despacho n. ${ }^{\circ}$ 11522/2008, II Série, nº79. Diário da Rebública, 22 abril 2008. 18353-18355.

PORTUGAL, PRESIDÊNCIA DO CONSELHO DE MINISTROS. Decreto-Lei n. ${ }^{\circ}$ 55/2018. Diário da República, 1. ${ }^{\text {a }}$ série - N. ${ }^{\circ}$ 129, 6 julho 2018. 2928-2943.

SEFTON-GREEN, J. (. ). Creative Learning. Londres: Arts Council England - Creative Partnerships, 2008.

SELTZER, K.; BENTLEY, T. The Creative age: Knowledge and skills for the new economy. London: Demos, 1999.

SILVA, T. T. D. Teorias do currículo: uma introdução crítica. Porto: Porto Editora, 2000.

THOMSON, P.; SEFTON-GREEN, J. (Eds.). Researching Creative Learning: methods and issues. London: Routledge, 2011.

THOMSON, P.; SEFTON-GREEN, J. (Eds.). Researching Creative Learning: methods and issues. London: Routledge, 2011.

TORRANCE, E. P. Criatividade: medidas, testes e avaliações. São Paulo: Ibrasa, 1976. 


\section{Correspondência}

Carla Sofia Prata Ramos Pereira: Doutora em Educação, na Especialidade: Formação de Professores. Pesquisa junto ao Instituto de Educação da Universidade de Lisboa, Portugal.

E-mail: pratapereira@gmail.com

Texto publicado em Currículo sem Fronteiras com autorização da autora 